[Duncan, J., Bowden, C., \& Smith, A. (2005). Reviewing and Rethinking Parent Support and Parent Education Opportunities in New Zealand. New Zealand Annual Review of Education, 14, 153-169]

\section{Reviewing and Rethinking Parent Support and Parent Education Opportunities in New Zealand}

\section{JUDITH DUNCAN, CHRIS BOWDEN AND ANNE SMITH}

\section{Abstract:}

This article examines some of our current understanding about parent support and parent education approaches. We suggest that early childhood centres in New Zealand currently undertake valuable and worthwhile parent support through their present programmes and curricula, and argue that they should be enabled to continue the key role they already play in New Zealand for family support. This review is part of a wider study undertaken for the Ministry of Social Development on early childhood centres and family resiliency.

$T^{1}$

his article begins with a select review of current New Zealand and international literature on parent education and support programmes. These are considered in the context of a small-scale qualitative study examining the ways that early childhood centres support family/whānau ${ }^{1}$ resilience, undertaken for the New Zealand Ministry of Social Development in 2001. Debate on parent education and support often focuses on early intervention programmes or targeted funding, and resourcing is often directed to isolated, or "one-off", workshops (including television campaigns or pamphlet circulations), or imported parent education programmes. In presenting some key findings from this study we argue that the current ways of working within our New Zealand early childhood settings offer meaningful support in everyday situations for parents and family/whānau and are consistent with the literature on effective parent support. We propose that resourcing early childhood education settings to both increase participation and quality would be a productive policy direction.
154 Judith Duncan, Chris Bowden and Anne Smith

According to Lee and Thompson (2000), identifying parent strengths and building on them while offering appropriate assistance (where this is needed), are characteristics of effective parent support services. Parent education and support includes informal support from kin and communities, as well as various types of formal services such as parent education and support groups or courses, drop-in centres, home-visiting programmes, information and community referral services, health education and social service professional contact, or institution-based support such as that offered through schools and early childhood centres.

The goals of family support programs focus on enhancing the capacity of parents in their child-rearing roles; creating settings in which parents are empowered to act on their own behalf and become advocates for change; and providing a community resource for parents. (Weissbourd \& Kagan, 1989, p. 29)

Public response to difficulties experienced by children in disadvantaged circumstances often focuses on what can be done to change parenting which is perceived to be inadequate. Yet the complex and often difficult circumstances of the lives of families, and the firmly held values and beliefs within them, sometimes make the intrusion of well meaning efforts to "fix" families problematic. There are also major limitations to research and knowledge about effective parenting (Gorman \& Balter, 1997; McMillan, 1997; Powell, 1997).

\section{Evaluating Parent Education Programmes}

In Aotearoa/New Zealand there is resistance to the importation of overseas parent education programmes developed in an entirely different cultural context (Pihama, 1996). Deficit models have been critiqued, and there is an awareness of the dangers of dominant pakeha approaches silencing Māori perspectives on family/whānau practices (Bishop \& Glynn, 1999; Rohx, 2000; Stephenson \& Ranginui-Charlton, 1994). The assumption that professionals or other people in power can determine what parents need has also been seriously questioned (Powell, 1997). Powell emphasizes the importance of a partnership between parent educators and parents in parent/education support programmes.

Individuals should be responsible for generating responses to their own needs or situations. Three guidelines for family support practice are illustrative: staff and families work together in relationships 
based on equality and respect; families are resources to their own members, to other families, to programmes, and to communities; and programmes affirm and strengthen identities and enhance their ability to function in a multicultural society. (Powell, 1997, p. 10)

Stephenson and Ranginui-Charlton (1994) found that Māori families do not always perceive mainstream health services as supportive, which has led to the development of more culturally appropriate Māoriprovided programmes on maraes and through local iwi-based services. In order to provide culturally appropriate professional advice, it is important that health services are based within local communities and delivered by staff with an understanding, knowledge and experience of the culture.

A wide variety of parent education and support programmes are available in New Zealand, including Parents as First Teachers, HIPPY, ${ }^{2}$ and Family Start. There is little evidence, however, to support the superiority of any one model for changing disciplinary practice (First \& Way, 1993; Gorman \& Balter, 1997; Howard, 1996) It is valuable, however, to identify the characteristics of parent education programmes which are most likely to work to achieve change. Smith (2002)identified four principles of effective early intervention programmes (most of which involved working with parents). The first principle involved timing and maintenance, and indicates the importance of taking action in the early years of children's lives, and of continuing input rather than brief interventions. The second principle relates to programme intensity and quality. More intensive programmes (such as home visits once a week rather than once a month) and high quality interventions are most likely to be effective. The third principle was that broad, flexible programmes which include provision of direct experience for children achieve stronger effects. The fourth principle concerned the importance of the macrosystem and the need for change to occur in a wider climate of support for children and families.

How a parent education programme was actually experienced by parents, was explored by First and Way (1995). The programme under study was offered through a group-based community education initiative in an urban early childhood centre. Most of the mothers came from poor family backgrounds, were members of minority ethnic groups, and had stressful living situations. The programme helped the women to think critically about their situation and attempt new ways of interacting with their children. They changed from being depressed and angry to becoming more empathetic towards their children, and were led to solve their family problems in more proactive ways. Mothers talked about their change in thinking and behaviour to a more positive approach to discipline. The authors recommend a transformative learning approach to parent education, in order to enhance parents' capacity for critical thinking. They believe that women in high risk situations do have the capacity for critical reflection and the potential to change, and that they can achieve a heightened feeling of purpose and control in their lives. A group situation can, therefore, provide a useful trigger to stimulate changes in parenting.

However, Halpern (1993) argues that parent education programmes for families in poverty can be used as a substitute for providing adequate income and economic opportunity, and characterised by an ambivalent attitude to poor people. He believes that such programmes often ask for more from families than they can reasonably deliver, given the circumstances of their lives.

We turn the imperative for addressing poverty, which is found in basic, shared ideals and myths back on the poor themselves, arguing for example that if the poor want access to the American ideals of equal opportunity and social mobility, they must try harder, must behave in ways prescribed by those who are not poor, and must in effect give something back to society. (Halpern, 1993, p. 160)

This attitude about fixing the parenting of families in poverty is also prevalent in New Zealand. Programmes of economic reform (Atwool, 1999) have radically worsened the situation for children and families in poverty, and at the same time done little to provide the support which might prevent the problems. Atwool argues that adequate provision of resources through preventive and early intervention will reduce the need for remedial action against child abuse. Chamberlin (1996) has also argued that the piling up of risk factors in society leads to family problems.

An alternative approach is to ensure that basic preventive services such as health care, early childhood education and parent support programs are available to all families and children in a given community. Primary prevention works by preventing low- and medium-risk families from becoming high risk. (Chamberlin, 1996, p. 2)

Family support research implies the need for those working with families to have basic education, ongoing professional development, empathy with parents, detailed experiential knowledge, and sympathy 
and understanding for local communities. Affirming parents' expertise and experience, and being sensitive to the complexity and stress of the context of families' lives, is important. If discussion about parenting takes place within the context of normal routines and conversations, and simple alternatives which work in real life contexts are offered, professional contact is likely to be more effective. It is unlikely that change will be achieved if professionals are unable to connect with parents within their everyday life contexts. It is also unlikely that change will be successfully achieved with a top-down expert-to-parent approach. A partnership approach is much more likely to be effective. Working with high risk families requires more intensive and broad community-based interventions, which do not focus only on parenting but address wider issues, such as lack of income, unemployment, housing, and poor access to early childhood education and good health care (Atwool, 1999; Chamberlin, 1996; Halpern, 1993; Powell, 1997).

\section{Early Childhood Services}

Early child hood (EC) services provide a valuable point where education and self-help options can be introduced to families. EC centres can bring families together to share common dilemmas (in parenting, for example) with staff and others, and can build upon their capacity to diffuse crises and inform future actions. Should professional interventions and support be required, EC staff can assist families by introducing them to local practitioners, something which is more likely to be welcomed than a cold referral to an "outside" agency.

EC centres can help families develop supportive relationships/ networks and in doing so influence the amount and quality of social capital available to them in times of crisis. Families in crisis should have access to both personal, family and community developmental programmes and support services of high quality. EC centres could therefore be viewed as a strong and timely resource for families to draw upon.

\section{Participation}

While the family is the primary institution influencing the development of young children, participation in early childhood education has been shown to have effects on long- and short-term outcomes for children, particularly for children from disadvantaged families. Unfortunately, Māori and Pasifika children are less likely to participate in EC centres, compared to other ethnic groups. A Department of Labour study showed that 48 percent of Pacific Island children, 53 percent of Māori children and 66 percent of Pakeha children attend early childhood centres (Department of Labour, 1999; Smith et al., 2000). Centres catering for Māori children usually have a strong focus and reliance on whānau/community participation and linkages (Mara, 2000; Rohx, 2000), and the extent to which early childhood centres can build on these is likely to determine both the participation of children and their success in supporting families.

The question of whether children's participation in early childhood centres also helps enhance and support low-income families in their role as primary caregivers, and in strengthening their resources, is important, yet relatively unexplored territory. Research has established that good quality early childhood education can contribute to ameliorating the effects of poverty and risk for children (Barnett, 1998; Smith et al., 2000). It cannot solve the problem of poverty, but it can help families and whannau cope with the stresses and challenges of modern day life. Early childhood education should not, however, be considered the only context for intervention with families and whānau in need. It can and should be considered as a valuable part of the solution to the problems facing modern families and whannau that requires a multi-perspectival and multi-sector approach.

Early childhood intervention alone cannot transform lives. Its positive effects can be overpowered by the longer and larger experience of growing up in poverty ... no program can enable children to develop optimally when their larger rearing environment is not conducive to optimal development. Early intervention can help, but it must not be considered more than one piece of the solution to the problem of poverty. (Zigler \& Styfco, 1993, cited in Smith, 1996, p. 3)

Hayden and MacDonald (2001) argue that early childhood centres are well situated to adopt a new focus which would give them more than a purely child-centred role. They argue that it is time to transcend the traditional discourses that view early childhood centres as support for working parents, as compensatory programmes for children with additional needs (disadvantaged children) and as programmes for developing school readiness. By changing attitudes and policies, early childhood services can be reformulated to assume the critical task of developing and facilitating social relationships, networks and interagency collaborations, and take a central role in building communities and civil society. Hayden and MacDonald argue that early childhood 
centres should be seen as offering a service to the community, and advocate the development of a new discourse that incorporates a community-oriented approach to service delivery. This discourse would recognise that many early childhood centres and services help build community connectedness by being a vehicle whereby links, relationships and opportunities for networking develop - both on a micro, personal level between families and early childhood centres, and on a community level between agencies and organisations, early childhood centres and families.

\section{Current international trends}

The current trend internationally in early childhood education is to take a comprehensive approach that focuses not only on children, but also on their families (Powell, 1997). A "family systems" perspective (St. Pierre \& Layzer, 1998) suggests that programmes which focus only on children will not produce the best results. Programmes which are delivered to whole families are more likely to be effective in breaking the cycle of poverty. Head Start Family Services and programmes such as the New Chance and the Comprehensive Child Development Program in the United States are initiatives which have focused on the whole family and its multiple needs for services. In an OECD report (Organisation for Economic Cooperation and Development, 2001) which reviewed EC provisions in twelve countries, the reviewers identified key programmes which linked early childhood centres, parents and communities through meaningful and supportive mechanisms. The authors argued that EC programmes can strengthen and build social cohesion between families, communities and government and non-governmental sectors. They identified how multi-agency initiatives incorporating early childhood provisions more adequately meet the needs of today's parents, and when located in areas of high need promote equal educational opportunities without stigmatising individual children (p. 84). They offer several international examples of these forms of provision, including that in England:

Early Excellence Centres, government supported models of exemplary practice, [which] offer a range of integrated services, including early years education for 3-4 year olds, full-day care for children birth to 3 years, drop-in facilities, outreach, family support, health care, adult education and practitioner training. (p. 84)

Wigfall (2002) describes the "one-stop-shop" approach taken by the Coram Community Campus, an innovative model of service provision in inner London, where a range of services for young children and their families include care, education, health, parent support and other services (for example, a child psychologist and social worker) on one site. This approach was developed in order to overcome the problem of compartmentalisation and fragmentation in traditional children's services, and is based on research supporting the importance of early preventive work with parents in supporting resilience.

\section{Aspects of quality}

The extent to which early childhood programmes incorporate "quality" is likely to influence their effectiveness as sources of support for families. There is considerable evidence (Smith et al., 2000) that quality influences the degree to which favourable child outcomes result from children's participation in early childhood education. Quality has been defined as "the essential components of early childhood environments which are valued in our society, and which support the well-being, development and rights of children, and support effective family functioning" (p. 44). Quality relates to the nature of the early childhood microsystem, including the roles, relationships and activities in which children and families participate. Structural aspects of quality include adult:child ratios, child group size, staff training and education, staff stability; process quality refers to the general environment of social relationships and interactions between centre staff, children and their families. Both structural and process quality influence outcomes for children, and are therefore likely to be very relevant to their effectiveness in supporting family resilience. It is, for example, important for staff to be accessible to families, and professional in their communications with them, and this is influenced by structural factors such as adult:child ratios and staff training. The processes through which staff interact and relate to families are also likely to be a key aspect of their effectiveness as a support for families. If staff are able to engage in a positive and reciprocal manner with families, rather than in a distant or detached manner, then they are more likely to support family strengths.

\section{Support mechanisms}

Early childhood centres and staff may help children become resilient by providing quality educational environments which enable them to develop attachments to staff, and by assisting families to provide more sensitive and nurturing home environments, thus facilitating secure attachment of children to their parents. Early childhood staff may 
develop beneficial secure attachments with children, too, and so foster the development of similar relationships between parents/caregivers and children (Howes \& Hamilton, 1992). They can foster such relationships by modelling them within the early childhood centre, and by working alongside parents to help them become more responsive nurturers and providers.

An early childhood centre can also be conceived of as a secondary caregiving and learning environment which can play an important protective role in the lives of both children and families. Early childhood centres which have well trained staff, who are sensitive to family stresses and know how to communicate and relate to families supportively, can provide a safe nurturing place. They can provide opportunities for children and families to develop skills and a sense of achievement and worth. Early childhood staff may help children and families (particularly those who live in "toxic" environments) that they can develop knowledge, skills and abilities that will enable them to better manage their circumstances, their pain and vulnerability, and build for themselves a better life.

It is within this context that the authors undertook a small-scale qualitative study to investigate how EC centres support family resilience. The findings from our study support the literature reviewed, and confirm that EC centres are seen to provide meaningful and valuable parent support and parent education, in addition to their work with children.

\section{Early Childhood Centres and Family Resilience}

\section{The wider study}

The wider study, entitled Early Childhood Centres and Family Resilience ${ }^{3}$ interviewed families/whānau, staff from three EC centres, and advisory support agencies on how the support offered by EC centres made a difference to the lives of individual family members and the family as a unit. It examined the ways that EC centres indirectly supported the development of resilience in individuals and families, and focused on identifying the policies and strategies of EC centres that helped families develop social capital (their own family resources) and assisted them in coping with challenging and stressful times. The study also examined the ways that centres encouraged the development of social capital by helping families to establish supportive networks and relationships with other sources of support.
Methods

For each EC centre we used a combination of methods to gather as many perspectives on the EC centre as possible. A participant observer spent time in the EC centre observing the interactions between staff and families. The staff kept reflective journals on their interactions with parents on a daily basis and they were interviewed as a group on their centre's aims, philosophies and practices with families. Families volunteered and were interviewed on their experiences with the EC centre, and key agency representatives were interviewed on their views on the effectiveness of the support, which the nominated EC provided for families. The wider study itself was set within an ecological framework, and considered the links between the families, the EC centres, and the community as important factors to be considered (Duncan, Bowden \& Smith, 2004).

\section{Findings}

\section{Planned parent educational programmes}

While there is an expectation in New Zealand centres that parent education programmes will be provided, on a regular or semi-regular basis, we were interested to discover that neither the parents, nor the staff of the EC centres, perceived that these were effective in any way. The participants provided several reasons for this:

Firstly, the EC staff and support providers identified that they often work with families who are preoccupied with survival (e.g., getting food on the table, paying the rent) and for these families attending parenting courses and learning more about child development was not necessarily a high priority. Secondly, the parents were often too tired to attend, because of their long hours of employment, or because they were stressed and drained from supervising their children. Likewise, the meetings were often scheduled at times when parents did not have access to child care to allow them able to attend, or were working themselves at the time. Thirdly, it was highlighted by several families and several support agencies that EC centres often ran workshops on issues that were not priorities to families who were struggling with difficulties.

In every early childhood centre surveyed, all participants - the staff, support agency representatives and the parents - raised issues and concerns that the planned parent programmes and workshops in early childhood centres did not meet family needs or interests. While these 
programmes took considerable time and work to organise and run for the staff at the centre, and for those other people and organisations that were involved, their usefulness and relevance need to be reconsidered.

Working alternatives which offered meaningful support in the EC centre While the range of formal parent education and support programmes that the participants were offered did not meet the families' needs, there were other provisions which did. These provisions were all part of the informal relationships and roles of the EC centres. Actively promoting the family as part of the centre community was an important philosophical goal of the three centres included in this study. Once these relationships were established, the staff then often found themselves as the "trusted advisor", supporting parenting and encouraging involvement of parents in their children's lives. Likewise, introducing families to other members of the EC community became an important role, both in terms of supporting friendships and links between parents, and by introducing referral agencies and support personnel from outside the immediate EC community.

Building relationships with the wider family and whannau

Building relationships with the family of the children in their care was an important philosophy and goal for staff of all three centres. They regarded supporting the whole family as part of their job. They hoped that they had created an environment where families felt welcomed and comfortable and would come and talk with staff about issues and problems. It was observed by the researchers that staff seemed to know the families well, and had a sense of understanding about who needed and welcomed the interactions - and when it was appropriate or not. It was also clear from the observations that these daily or on-going interactions provided opportunities for staff to observe any immediate stresses or pressures on families. Informal chats and conversations not only helped parents/caregivers feel welcome, and demonstrated that staff took an interest in their lives as well as the life of their child(ren), but they also provided opportunities for information sharing and relationship building. This "taking a genuine interest" in the lives of family members was a strategy that was identified as helping families feel welcome, and supported.

Providing links for other relationships and friendships

The early childhood centres were also identified by many parents and staff as providing opportunities and spaces for parents to access, form, and maintain social relationships with other families. There were three main structured opportunities at the centres for parents to meet other parents: participation in the programme; attending social events and activities (or parent education/information evenings); and becoming a member of the parent/management committees.

Participating in the programme was an important variable in making contacts through the centre. It appears from the reporting of the participants that the level of involvement that parents had within the centre greatly affected the number and type of relationships they developed with other families. For example, those parents who reported that their level of involvement was restricted to dropping their children off, and who did not want a great deal of involvement with their EC centre, tended not to report having made friendships or having developed relationships with other families through the centre. By way of contrast, others who reported having at least some involvement in the centre did develop relationships with other parents, both within the centre setting and also beyond it.

Centre-organised social events and activities (e.g., fundraisers, working bees, cultural nights, shared meals) appeared to be a successful means of connecting families. These gatherings allowed parents/ caregivers to share information, discuss issues, raise concerns and seek help. In several cases, providing a point of contact and place for them to meet with common interests led to their forming relationships and becoming involved in other activities outside of the EC setting. This was particularly supportive for parents who had difficulty making friendships and felt they were isolated within their community.

\section{Discussion and Conclusion}

While the main role of EC centres and staff is most often seen as providing support for children, there is ample evidence that demonstrates that EC centres and staff also provide effective and valuable support to family and whānau members. The findings in this study are consistent with the reviewed literature on meaningful parent education and support. As identified in this review, effective support occurs when it:

- $\quad$ builds on parent strengths (Lee \& Thompson, 2000);

- provides support in every-day settings (Atwool, 1999; Chamberlin, 1996; Halpern, 1993; Powell, 1997); 
- is delivered by staff who acknowledge the complexities of parent and families/whānau lives (Stephenson \& Ranginui-Charlton, 1994);

- is regular and intense (Smith, 2002).

Other outcomes also cited in the literature are:

- enhancing the child-rearing roles of parents (Weissbourd \& Kagen, 1989),

- strengthening attachment bonds with their child(ren), and

- greatly improving family relationships generally (Howes \& Hamilton, 1992).

The study also demonstrated the importance of parent participation in the centre, as not only of value to the child, but as playing a significant role in developing friendships and links amongst the EC community. These, then, are effective mechanisms that EC centres currently provide in their daily programmes for participating families.

While New Zealand has not developed the same range or intensity of fully integrated multi-agency services as other European countries have, there is a strong philosophy that mainstream early childhood education programmes have a major role in supporting families. The early childhood curriculum guidelines, Te Whăriki (Ministry of Education, 1996a) has as one of its five major goals, "Belonging" for children and families, which encourages the development of connecting links between early childhood centres and families. "The families of all children should feel that they belong and are able to participate in the early childhood education programme and in decision making"(Ministry of Education, 1996a, p. 54).

How this philosophy translates into action, and what this "best practice" in New Zealand early childhood centres looks like, is still relatively unknown. New Zealand's Early Childhood Strategic Plan Pathways to the Future: Ngā Huarahi Arataki (Ministry of Education, 2002) has three main goals, and one of these is "to promote collaborative relationships" (p. 2) and this clearly means relationships between parents and teachers, and other professionals who work with families.

A child's learning and development depend not only on the ECE environment they experience, but also on their home and wider social environment. The coming together of children and families in ECE services provides greater opportunities for addressing health and social issues. Building stronger links between ECE services, antenatal programmes, parents and whānau, parenting programmes, schools, and health and social services can also improve a child's educational achievements. Collectively, these services allow their learning and development needs to be met more holistically. (p. 9)

Research and experience have told us that EC services provide a valuable point of focus where education and self-help options can be introduced to families. EC centres can bring families together to share common dilemmas (for example, in parenting) with staff and others, and can build upon their capacity to diffuse crises and inform future actions. EC centres could therefore be viewed as a resource for families to draw upon, a place where they can develop supportive networks and relationships, and in so doing influence the amount and quality of social capital available to them in times of crisis.

Resources directed to increasing quality and participation in EC centres, as well as improved staffing levels, should be a priority over developing formal parenting programmes and running workshops that are difficult to target and often under-used. Arguably, increasing participation in early childhood education, and encouraging staff and families to talk informally in their local EC centres, should together offer real opportunities for better support to be offered. In this way, appropriate parenting guidance can be provided and shared, to the long-term benefit of children, families and whānau.

Notes

1. Whānau is the Māori term to describe family. This term, however, embraces the concept of the "extended" family, and requires a much wider understanding of family grouping than that determined by just the "nuclear family" based on blood relations.

2. Home Instruction for Parents of Preschool Youngsters (HIPPY) is a parent involvement, school readiness program that helps parents prepare their three, four, and five year old children for success in school and beyond. It is based in the home where parents work as their children's "first teacher".

3. The full report is soon to become available on the Ministry of Social Development website < www.msd.govt.nz $>$. 


\section{References}

Atwool, N. R. (1999). New Zealand children in the 1990s: Beneficiaries of New Right economic policy? Children and Society, 13, 365-379.

Barnett, W. S. (1998). Long-term cognitive and academic affects of early childhood education and poverty. Preventive Medicine: An International Journal Devoted to Practice \& Theory, 27(2), 204-207.

Bishop, R., \& Glynn, T. (1999). Culture counts: Changing power relations in education. Palmerston North: Dunmore Press.

Chamberlin, R. W. (1996). "It takes a whole village": Working with community coalitions to promote positive parenting and strengthen families. Pediatrics, 98(4), 803-807.

Department of Labour and National Advisory Committee on the Employment of Women. (1999). Childcare, families and work: The New Zealand childcare survey 1998. A survey of early childhood education and care arrangements for children. Wellington: Labour Market Policy Group.

Duncan, J., Bowden, C., \& Smith, A. B. (n.d.) Early childhood centres and family resilience. Report prepared for the Ministry of Social Development.

First, J. A., \& Way, W. L. (1995). Parent education outcomes: Insights into transformative learning. Family Relations, 44, 104-109.

Gorman, J. C., \& Balter, L. (1997). Culturally sensitive parent education. Review of Educational Research, 67(3), 339-369.

Halpern, R. (1993). The societal context of home visiting and related services for families in poverty. The Future of Children, 3(3), 158-171.

Hayden, J., \& MacDonald, J. J. (2001). Community centred childcare: A new answer to (who benefits)? Journal of Australian Research in Early Childhood Education, 8(1), 33-40.

Howard, D. E. (1996). Searching for resilience among African-American youth exposed to community violence: Theoretical issues. Journal of Adolescent Health, 18, 254-262.

Howes, C., \& Hamilton, C. E. (1992). Children's attachment with their child care teachers. Child Development, 62, 867-878.

Lee, M. D., \& Thompson, R. A. (2000). Creating supportive communities for families with young children. Clemson University, SC: Institute on Family and Neighborhood Life.

McMillan, B. (1997). Parents as parents first. Childrenz Issues, 1(2), 31-35.
Mara, D. (2000). Response to Miriam K. Rosenthal: A Pacific Island perspective. Childrenz Issues, 4(1), 18-19.

Ministry of Education. (1996a). Te Whāriki: Early Childhood Curriculum. Wellington: Learning Media.

Ministry of Education. (1996, October 3). Revised statement of Desirable Objectives and Practices (DOPs) for chartered early childhood services. New Zealand Education Gazette, insert.

Ministry of Education. (2002). Pathways to the Future: Ngā Huarahi Arataki. Wellington: Learning Media.

Organization for Economic Cooperation and Development (OECD). (2001). Starting strong: Early childhood education and care. Paris: OECD.

Pihama, L. (1996). Policy constructions: In whose interest? A Critical analysis of PAFT in relation to Maori education. Social Policy Journal of New Zealand, 7, 108-123.

Powell, D. (1997). Parent support programmes: Opportunities and challenges. Childrenz Issues, 1(2), 9-11.

Rohx, H. (2000). Response to Miriam K. Rosenthal: A Māori perspective. Childrenz Issues, 4(1), 16-17.

Russell, M. (1996). The discipline of children: Alternatives to smacking. Unpublished masters thesis, Victoria University of Wellington, New Zealand.

Smith, A. B. (1996, April). How does being on a low income affect parents' ability to choose and access a high quality early childhood centre? Paper presented at conference "The Multiple Effects of Poverty on Children and Young People: Issues and Answers", Auckland.

Smith, A. B. (2002). The impact of early experience: What are the main principles? Childrenz Issues, 6(2), 44-46.

Smith, A. B., Grima, G., Gaffney, M., Powell, K., Masse, L., \& Barnett, S. (2000). Strategic research initiative literature review: Early childhood education. Wellington: Ministry of Education.

Stephenson, S., \& Ranginui-Charlton, M. (1994). Parent support: A review of the literature. Hamilton: Special Education Services Trust.

St. Pierre, R. G., \& Layzer, J. I. (1998). Improving the life chances of children in poverty: Assumptions and what we have learned. Social Policy Report (Society for Research in Child Development), 7(4), 1-28.

Weissbourd, B., \& Kagan, S. L. (1989). Family support programs: Catalysts for change. American Journal of Orthopsychiatry, 59(1), 20-31. 
Wigfall, V. (2002). “One-stop shopping” : Meeting diverse family needs in the inner city? European Early Childhood Education Research Journal, 10(1), 111-121.

\section{The authors}

Dr Judith Duncan is a Lecturer and Senior Researcher with the Children's Issues Centre, University of Otago, Dunedin. She has been a kindergarten teacher (3-5 year olds), and subsequently lecturer in ECE at both the Dunedin College of Education and the Education Department of the University of Otago. Her research interests are focused on early childhood policy and practice, and she is currently working on a variety of early childhood research projects which examine children's and teachers' experiences in early childhood settings.

Chris Bowden is a lecturer in the School of Education Studies, Victoria University of Wellington. Chris's research interests include the area of suicidology, youth suicide prevention and more recently suicide prevention in tertiary education settings. His recent work has included informing the development of resources that aim to assist families, support agencies, and communities improve their responses to suicide and suicidal behaviour.

Professor Anne Smith took up her present position of Director of the interdisciplinary Children's Issues Centre at the University of Otago in 1995. She is the author of the well known book in child development, Understanding Children's Development (now in its fourth edition), amongst many other publications. Anne's particular interests in children include social cognition, friendships and social relationships, and how adults scaffold and support the development of children's thinking.

Judith and Anne can be contacted at the Children's Issues Centre, University of Otago, P O Box 56, Dunedin. Chris Bowden can be contacted at the School of Education Studies, Victoria University of Wellington, P O Box 600, Wellington.

The authors wish to acknowledge support from the Ministry of Social

Development for funding the study reported in this article. 